\title{
Enhanced Bio-Electrochemical Reduction of Carbon Dioxide by Using Neutral Red as a Redox Mediator
}

\author{
Hathaichanok Seelajaroen, ${ }^{[\mathrm{[a}]}$ Marianne Haberbauer, ${ }^{[\mathrm{b}]}$ Christine Hemmelmair, ${ }^{[\mathrm{b}]}$ \\ Abdalaziz Aljabour, ${ }^{[c]}$ Liviu Mihai Dumitru, ${ }^{*[a]}$ Achim Walter Hassel, ${ }^{[c]}$ and \\ Niyazi Serdar Sariciftci ${ }^{[a]}$
}

\begin{abstract}
Microbial electrosynthetic cells containing Methylobacterium extorquens were studied for the reduction of $\mathrm{CO}_{2}$ to formate by direct electron injection and redox mediator-assisted approaches, with $\mathrm{CO}_{2}$ as the sole carbon source. The formation of a biofilm on a carbon felt (CF) electrode was achieved while applying a constant potential of $-0.75 \mathrm{~V}$ versus $\mathrm{Ag} / \mathrm{AgCl}$ under $\mathrm{CO}_{2}$-saturated conditions. During the biofilm growth period, continuous $\mathrm{H}_{2}$ evolution was observed. The long-term performance for $\mathrm{CO}_{2}$ reduction of the biofilm with and without neutral red as a redox mediator was studied by an applied potential of $-0.75 \mathrm{~V}$ versus $\mathrm{Ag} / \mathrm{AgCl}$. The neutral red was introduced into the systems in two different ways: homogeneous (dissolved in solution) and heterogeneous (electropolymerized
\end{abstract}

onto the working electrode). The heterogeneous approach was investigated in the microbial system, for the first time, where the CF working electrode was coated with poly(neutral red) by the oxidative electropolymerization thereof. The formation of poly(neutral red) was characterized by spectroscopic techniques. During long-term electrolysis up to 17 weeks, the formation of formate was observed continuously with an average Faradaic efficiency of $4 \%$. With the contribution of neutral red, higher formate accumulation was observed. Moreover, the microbial electrosynthetic cell was characterized by means of electrochemical impedance spectroscopy to obtain more information on the $\mathrm{CO}_{2}$ reduction mechanism.

\section{Introduction}

Over the past decades, atmospheric carbon dioxide $\left(\mathrm{CO}_{2}\right)$ concentration has been increasing continuously and it is regarded as a major greenhouse gas. ${ }^{[1-3]}$ Thus, the reduction of atmospheric $\mathrm{CO}_{2}$ has attracted lots of interest as the carbon capture and utilization (CCU) processes. ${ }^{[4]}$ The $\mathrm{CO}_{2}$, as a carbon source, can be converted to several value-added products, ${ }^{[5,6]}$ such as carbon monoxide (CO), formic acids, acetic acid, methane, methanol and ethanol, through biological, ${ }^{[7-9]}$ electrochemi$\mathrm{cal}^{[10-13]}$ and photo(electro)chemical approaches. ${ }^{[14-18]}$ However, $\mathrm{CO}_{2}$ conversion requires a large energy input due to the fact

[a] H. Seelajaroen, Dr. L. M. Dumitru, Prof. Dr. N. S. Sariciftci

Linz Institute for Organic Solar Cells (LIOS)

Institute of Physical Chemistry, Johannes Kepler University Linz

Altenberger Strasse 69, 4040 Linz (Austria)

E-mail: hathaichanok.seelajaroen@jku.at liviu_mihai.dumitru@jku.at

[b] M. Haberbauer, C. Hemmelmair

The Austrian Centre of Industrial Biotechnology (acib GmbH)

Stahlstrasse 14, 4020 Linz (Austria)

[c] Dr. A. Aljabour, Prof. Dr. A. W. Hassel

Institute of Chemical Technology of Inorganic Materials (TIM) Johannes Kepler University Linz Altenberger Strasse 69, 4040 Linz (Austria)

$\square$ Supporting information and the ORCID identification numbers for the

(iD) authors of this article can be found under https://doi.org/10.1002/ cbic.201800784.

of (c) 2019 The Authors. Published by Wiley-VCH Verlag GmbH \& Co. KGaA This is an open access article under the terms of the Creative Commons Attribution License, which permits use, distribution and reproduction in any medium, provided the original work is properly cited. that $\mathrm{CO}_{2}$ is in a highly stable and low energy state. According to the thermodynamic reduction potentials, a one-electron reaction from linear $\mathrm{CO}_{2}$ to its bent anionic form $\left(\mathrm{CO}_{2}{ }^{--}\right)$requires a high potential of $-1.90 \mathrm{~V}$ versus standard hydrogen electrode (SHE). Compared to the single-electron process, the proton-coupled multi-electron reactions require substantially lower potentials. ${ }^{[16]}$ For example, the reduction potential of the $\mathrm{CO}_{2}$ reduction to formic acid $(\mathrm{HCOOH})$ involving two electrons and two protons, is $-0.61 \mathrm{~V}$ versus SHE. ${ }^{[16]}$ Nonetheless, the reduction potentials observed experimentally are much more negative than what thermodynamics predicts due to overpotentials. To overcome these high energy barriers, several approaches using catalysts were introduced. ${ }^{[19-27]}$

Among various $\mathrm{CO}_{2}$ reduction systems, the biological approach using microorganisms and enzymes as catalysts has been investigated due to the accessibility of catalysts from the biosphere compared to synthetically obtained catalysts. Moreover, biocatalysts provide high selectivity towards adducts and products and can be used under mild, ambient conditions without high temperature or high pressure. ${ }^{[28-30]}$ In the enzymatic approach, dehydrogenase enzymes have been reported as efficient catalysts for the $\mathrm{CO}_{2}$ conversion to alcohols, aldehydes and other hydrocarbons. ${ }^{[31]}$ Generally, these dehydrogenase enzymes only catalyze specific reactions with the requirement of a sacrificial cofactor. ${ }^{[31-33]}$ For example, formate dehydrogenase $(\mathrm{FDH})$ is known to catalyze the reduction of $\mathrm{CO}_{2}$ to formate with the aid of nicotinamide adenine dinucleotide (NADH) as a cofactor. ${ }^{[34,35]}$ Instead of using the sacrificial cofac- 
tors, the possibility of direct electron injection to dehydrogenase enzymes has been reported recently for electrochemical methods. ${ }^{[36-39]}$ However, the main limitation of using enzymes is that the enzymes are isolated from specific microorganism strains and the purification processes require trained personnel and specific equipment.

In contrast to enzymes, living biocatalysts (microorganisms) provide a great advantage in terms of sustainable systems due to their ability to reproduce. ${ }^{[40]}$ Compared to FDH, which is very often sensitive to an oxygen-containing environment, the structure of living microorganisms preserves the activity of enzymes inside due to their membrane and since they are able to reproduce themselves, new active enzymes are regularly generated. Additionally, the conversion efficiency of FDH for converting $\mathrm{CO}_{2}$ to formate is usually extremely low as compared to that for FDH converting formate to $\mathrm{CO}_{2} \cdot{ }^{[41]}$ Several microorganisms have been already investigated in the field of $\mathrm{CO}_{2}$ reduction for their capability of capturing and/or converting $\mathrm{CO}_{2}$ to valuable products by using electrons from electron carriers, such as hydrogen $\left(\mathrm{H}_{2}\right) \cdot{ }^{[42-44]}$ In the 1930 s, the first acetogenic bacteria (Clostridium aceticum) was investigated and the authors reported that $\mathrm{CO}_{2}$ and $\mathrm{H}_{2}$ could be converted to acetate, with the mechanism being described later on as the reductive acetyl-CoA or the Wood-Ljungdahl pathway. ${ }^{[45-48]}$ Moreover, the selectivity towards the products of $\mathrm{CO}_{2}$ reduction can be tuned corresponding to the local dehydrogenase enzymes of the microbial strains. Further investigation of these microorganisms reported that they are able to receive electrons either directly from the cathode or indirectly from the redox mediators of which the mechanism was called as extracellular electron transfer. ${ }^{[44]}$ Recently, Hwang et al. firstly reported the capability of Methylobacterium extorquens, which is known to be able to grow on reduced C1 compounds, to reduce $\mathrm{CO}_{2}$ to formate under aerobic conditions by using electrons supplied from an electrode through a mediator-assisted approach. $^{[49-51]}$

One possible approach to enhance the microbial electrosynthesis system is to introduce a redox mediator in order to facilitate the electron transfer from the electrode towards microorganisms' cytoplasmic membrane. According to previous studies, 3-amino-7-dimethylamino-2-methylphenazine hydrochloride (neutral red), known as a $\mathrm{pH}$ indicator and a staining dye, was used as an efficient redox mediator in several bio-electrochemical systems because its redox potential is close to that of the $\mathrm{NAD}^{+} / \mathrm{NADH}$ redox couple, which is one of the major electron carrier in the microbial electron transport chain. ${ }^{[22-54]}$ Moreover, it is known that neutral red can be polymerized electrochemically on various substrates, especially carbonbased ones, yielding a poly(neutral red) coating on the electrodes. ${ }^{[55]}$ As reported in previous studies, the resulting poly(neutral red) film was electrochemically active and chemically stable under biological conditions, and it has been widely used for bio-electrochemical applications similar to those of the monomer, such as sensors ${ }^{[56]}$ and $\mathrm{NAD}^{+} / \mathrm{NADH}$ regeneration. ${ }^{[57]}$ From a practical point of view, a system containing a redox mediator coated or directly deposited onto the electrode is preferred, rather than the homogenous approach (a redox me- diator dissolved in the electrolyte). This is firstly because product separation becomes easier and secondly because the electron transfer is greatly enhanced. ${ }^{[58-60]}$ Furthermore, such a system will have the advantage of long-term operation and lower mediator costs.

In this study, we further investigated the long-term performance of the microbial electrosynthetic cell (MEC) of M. extorquens by monitoring the products produced during the biofilm growth and $\mathrm{CO}_{2}$ reduction period. Additionally, the aid of neutral red as a redox mediator in an MEC system was investigated in two different approaches: homogeneous and heterogeneous ones. In the first approach studied, the cathode electrolyte contained soluble neutral red, whereas in the second approach the poly(neutral red) was directly coated onto the electrode.

\section{Results and Discussion}

\section{Inoculation of microorganisms}

M. extorquens biocathodes were developed in the two-compartment electrochemical three-electrode set-up as shown in Figure $1 \mathrm{~A}$. The cathodic compartment consisted of the

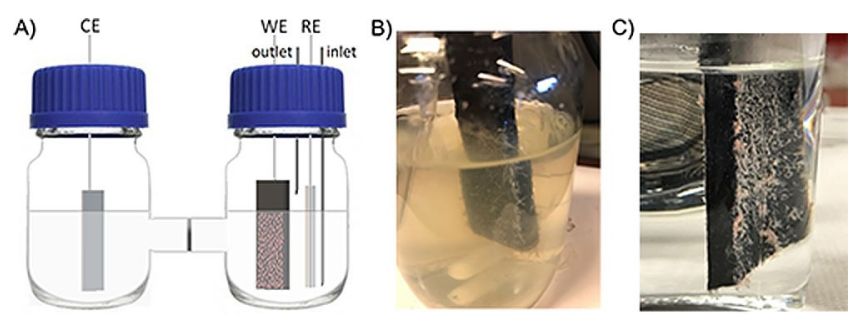

Figure 1. A) Schematic two-compartment three-electrode set-up for microbial electrosynthesis experiments, and biofilm formation after one-month inoculation on $\mathrm{B}$ ) the $\mathrm{CF}$ electrode in the medium, and C) the PNR/CF electrode in $0.2 \mathrm{M}$ phosphate buffer solution $\mathrm{pH} 7.0$.

medium containing $10 \%(\mathrm{v} / \mathrm{v})$ of $M$. extorquens pure culture suspension equipped with a carbon felt (CF) working electrode and a $\mathrm{Ag} / \mathrm{AgCl}(3 \mathrm{M} \mathrm{KCl})$ reference electrode. The anodic compartment contained a $0.2 \mathrm{M}$ phosphate buffer solution at pH 7.0 equipped with a Pt plate counter electrode. A potential at $-0.75 \mathrm{~V}$ was applied constantly for a month under $\mathrm{CO}_{2}$-saturated atmosphere. The cathodic compartment was purged with $\mathrm{CO}_{2}$ approximately $2 \mathrm{~h}$ every week to keep the compartment saturated with $\mathrm{CO}_{2}$. Since $M$. extorquens is capable of extracellular electron transfer through their pili, it is able to take up the electrons directly from the electrode. ${ }^{[51]}$ Consequently, it can be inoculated electrochemically on a carbon-based electrode. After a few days of inoculation, the growth of the biofilm on the electrode could be observed and increased gradually by the inoculation time. After one month of inoculation, the CF electrode was covered with the biofilm as shown in Figure 1B. Additionally, the electrodes were dried under ambient conditions (pictures of electrodes are shown in Figure S1) overnight for optical microscope and SEM imaging as shown in 


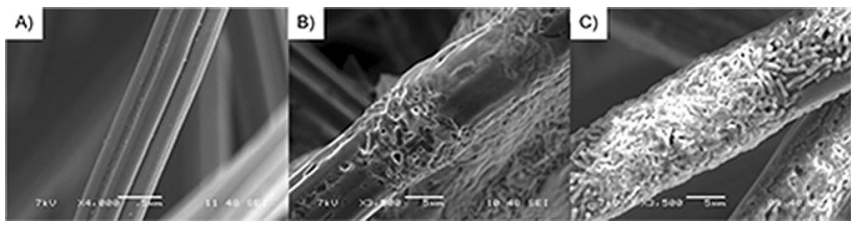

Figure 2. SEM images of A) bare $(F, B) C F$ with biofilm and C) PNR/CF with biofilm. Scale bar: $5 \mu \mathrm{m}$.

Figure 2. The optical microscopic and SEM images show characteristic pink-pigmented biofilm and rod-shaped cells of methylobacterium, confirming the growth of $M$. extorquens biofilm. ${ }^{[62,63]}$

During this period, headspace samples were collected daily and analyzed by gas chromatography (GC). The GC results showed that $\mathrm{H}_{2}$ was the only product detected in this phase. The amount of $\mathrm{H}_{2}$ produced is presented as a black line in Figure 3. The arrows indicate the period when the cathodic

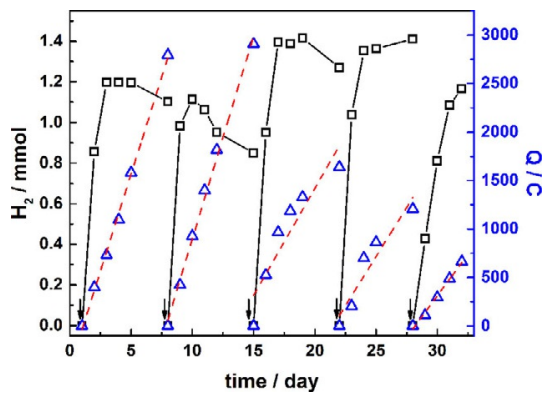

Figure 3. Amount of produced $\mathrm{H}_{2}(\square)$ and electrical charge consumed $(\mathrm{Q}, \triangle)$ during the inoculation period. The red dashed-lines show linear fitting graph of electrical charge consumption. The arrows indicate when the cathodic chamber was purged with $\mathrm{CO}_{2}$.

chamber was purged with $\mathrm{CO}_{2}$. The results reveal that $\mathrm{H}_{2}$ production was observed continuously and the highest $\mathrm{H}_{2}$ production was observed in the first day, immediately after $\mathrm{CO}_{2}$ purging with a production rate of $0.86-1.04 \mathrm{mmol} /$ day. However, the lowering in $\mathrm{H}_{2}$ amount in the third to fifth day of the cycle might be because the microorganisms consumed $\mathrm{H}_{2}$ as a reducing agent in their metabolisms as described in the WoodLjungdahl pathway. ${ }^{[64]}$ Furthermore, the electrical charges (Q) consumed during this period were plotted together in Figure 3 (blue data points). These results showed that the electrons were consumed constantly during this period, not only in the region where $\mathrm{H}_{2}$ was produced. The red dashed lines were plotted in order to present the linear fitting of charge data points. The fitting provides the rates of electrical charges consumed in each purging cycle which were found to be in the rage of $170.5-418.8 \mathrm{C} /$ day. The $\% \mathrm{FE}$ of $\mathrm{H}_{2}$ production in the growing phase was calculated for one day immediately after $\mathrm{CO}_{2}$ purging. The $\% \mathrm{FEs}$ were in the range of $35-98 \%$.

As the experiments were done in aqueous solution, $\mathrm{H}_{2}$ generation from electrochemical water-splitting has to be taken into consideration. However, we believe that the $\mathrm{H}_{2}$ produced during the inoculation period is produced by microorganisms themselves, as part of their metabolism. To confirm this, control experiments were carried out by constantly applying the same potential of $-0.75 \mathrm{~V}$ in the media by using a bare CF working electrode (without the biocatalyst). The experiments were done under $\mathrm{N}_{2}$ - and $\mathrm{CO}_{2}$-saturated conditions, and daily headspace samples were collected for a period of 1 week. The GC analysis revealed that no $\mathrm{H}_{2}$ was produced during the electrolysis of bare $\mathrm{CF}$ electrode in $\mathrm{N}_{2}$ - or $\mathrm{CO}_{2}$-saturated conditions (as shown in Figure S3 and S4). Considering the results obtained for these control experiments together with our observation that the production rate was increased after 2 weeks of inoculation related to the more biofilm formed on the electrode. Thus, we believe that the $\mathrm{H}_{2}$ constantly produced during the growth might be the product of microbial fermentation processes. ${ }^{[65]}$

In this work, we aimed to study the long-term performance of the biocathodes resulting from the inoculation of $M$. extorquens and the effect of neutral red as a redox mediator both when the redox mediator is dissolved in the solution and when it was coated on the electrode. Three different electrosynthetic systems were designed as MEC 1, 2 and 3. MEC 1 is defined as the electrosynthesis system equipped with the biofilm CF working electrode. In the second cell (MEC 2), we investigated the effects of neutral red as a redox mediator in the solution. Therefore, the cell was equipped with the biofilm CF as a working electrode and buffer solution containing neutral red as the electrolyte solution. In addition, to study the effects of the redox mediator when it was directly attached on the electrode, MEC 3 was developed by using the biofilm coated on $\mathrm{PNR} / \mathrm{CF}$ as a working electrode in mediator-free buffer solution.

\section{Electropolymerization of neutral red}

The PNR/CF electrode was prepared by the oxidative electrochemical polymerization and used as working electrode in MEC 3. The electropolymerization was performed in $0.1 \mathrm{M}$ phosphate buffer solution $\mathrm{pH} 6.0$ containing $1 \mathrm{~mm}$ neutral red at potentials between -1.0 to $1.0 \mathrm{~V}$ with the scan rate of $50 \mathrm{mV} \mathrm{s}^{-1}$ over 20 cycles as shown in Figure $4 \mathrm{~A}$, yielding a poly(neutral red)-coating onto the CF electrode (PNR/CF). In the first cycle, three oxidation peaks at $-0.39,0.20$ and around $0.8 \mathrm{~V}$ were observed. The first two redox couples indicated electrochemical features of protonated neutral red and its polymer, respectively. Another irreversible oxidation peak at around $0.8 \mathrm{~V}$ is referred to the formation of cation radical species that can initiate polymerization. These results are in agreement to the results reported previously. ${ }^{[55,57]}$ Upon polymerization, the current of the first two redox couples increased as more redox active polymer is formed on the electrode. Furthermore, a positive shift in the potential positions and broader features were observed. These phenomena could be related to the changes in the electrode surface and the branching of the polymer. After removal of the remaining monomer solution by rinsing with water, the resulting PNR/CF electrode was electrochemically characterized by cyclic voltammetry. CVs were 

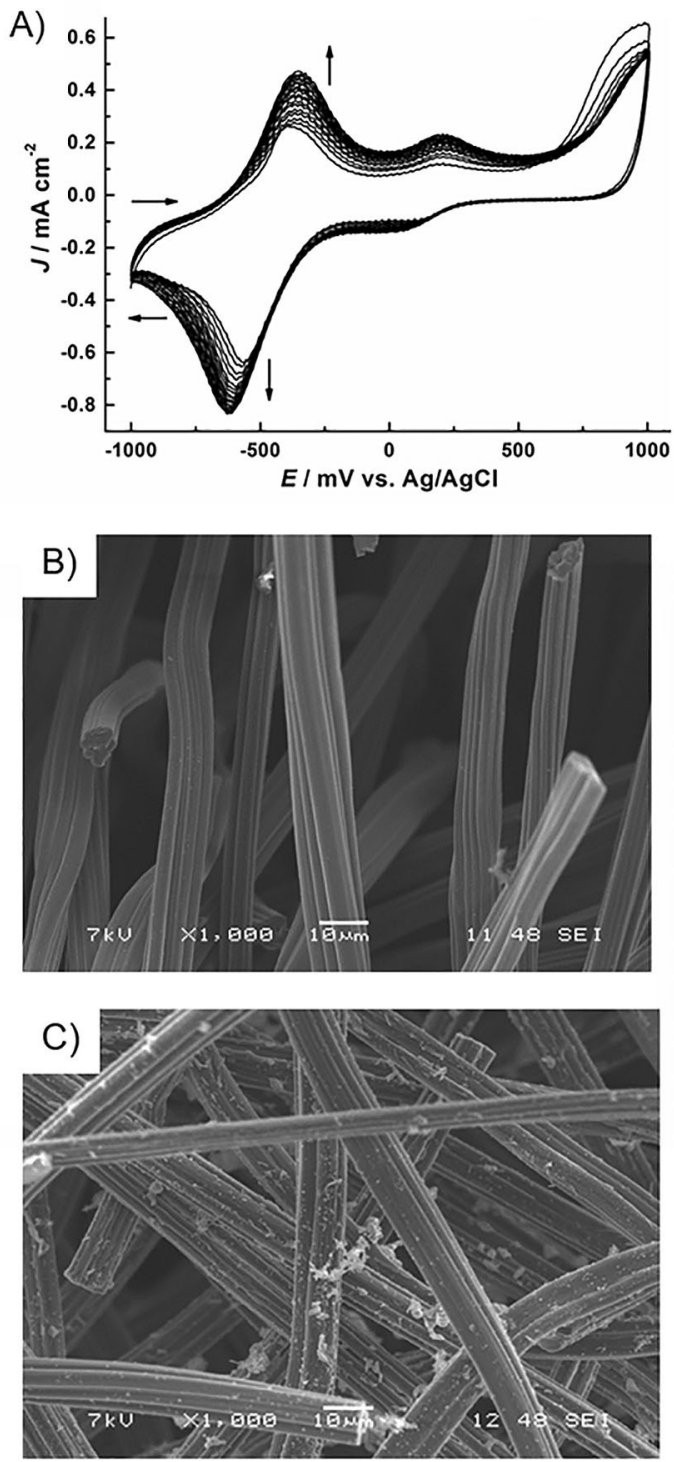

Figure 4. A) Cyclic voltammograms of neutral red electropolymerization onto a CF electrode: $1 \mathrm{~mm}$ neutral red in $0.1 \mathrm{M}$ phosphate buffer solution $\mathrm{pH} 6.0$ containing $0.1 \mathrm{M} \mathrm{KNO}_{3}$ at a scan rate of $50 \mathrm{mV} \mathrm{s}^{-1}$ over 20 cycles (arrows show the development of the cyclic voltammograms with cycles) and SEM images of B) a bare CF and C) PNR/CF. Scale bar: $10 \mu \mathrm{m}$.

recorded in $0.1 \mathrm{M}$ phosphate buffer solution $\mathrm{pH} 6.0$ at different sweep rates $\left(5,10,25,50\right.$ and $\left.100 \mathrm{mV} \mathrm{s}^{-1}\right)$. Two redox couple peaks were observed corresponding to those of monomer peaks, showing the electrochemical monomer-related features of the resulting film as shown in Figure S5. Furthermore, the SEM images of PNR/CF and bare CF were shown in Figure $4 B$, revealing the formation of polymeric film.

With the similar manner to PNR/CF preparation, neutral red was electropolymerized onto $\mathrm{Cr} / \mathrm{Au}$-coated glass electrodes for FTIR and UV/Vis measurements. Figure 5 shows FTIR spectra of neutral red (red line) and poly(neutral red) (blue line) together with the proposed structure of poly(neutral red). The FTIR spectrum of poly(neutral red) shows characteristic absorption peaks at 1609,1185 and $812 \mathrm{~cm}^{-1}$, which are attributed to vibration of $\mathrm{C}=\mathrm{C}$ or $\mathrm{C}=\mathrm{N}$, in-plane bending of $\mathrm{C}-\mathrm{H}$ and deforma-
A)

B)<smiles>Cc1cc2nc3ccc(N(C)C)cc3nc2cc1N</smiles><smiles></smiles>

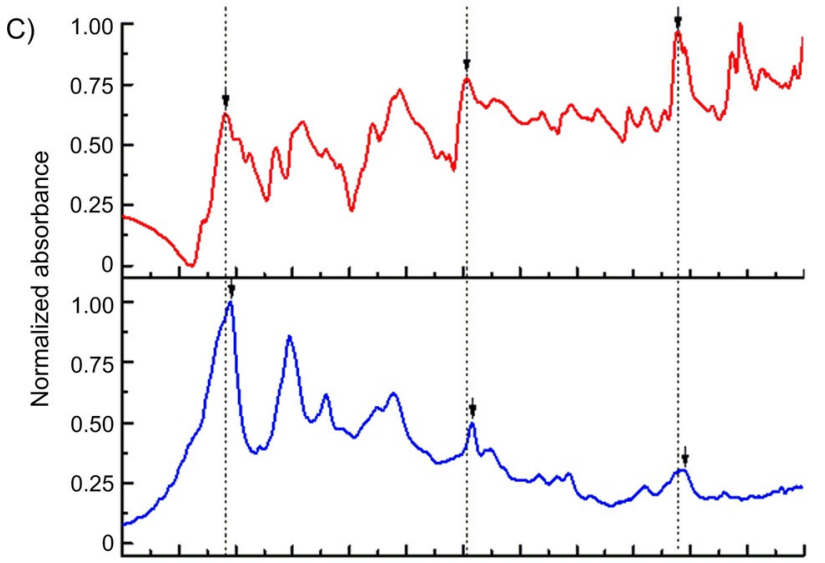

180017001600150014001300120011001000900800700600

Wavenumber $/ \mathrm{cm}^{-1}$

Figure 5. A) Structure of neutral red, B) structure of poly(neutral red) as proposed herein and C) FTIR spectra of neutral red $(\longrightarrow$ and poly(neutral red) $(-)$.

tion of aromatic ring, respectively. ${ }^{[66]}$ The absorption peaks of

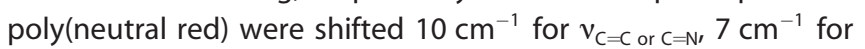
$\delta_{\mathrm{C}-\mathrm{H}}$ and $9 \mathrm{~cm}^{-1}$ for aromatic ring deformation towards negative wavenumber, compared to those of neutral red monomer. The shifts referred to increase in $\pi$-conjugation of the polymer. Additionally, UV/Vis absorption of the polymeric film was investigated, the spectra for which are shown in Figure S6. The absorption spectra exhibit maxima at wavelengths of 531, 500 and $455 \mathrm{~nm}$ for neutral red aqueous solution, drop-casted neutral red monomer, and poly(neutral red) film, respectively. The absorption spectrum of poly(neutral red) film was consistent with its of monomer with broader features, which is attributed to higher aggregation of aromatic rings in the polymeric layers.

\section{Long-term microbial electrosynthesis}

After one-month inoculation, the electrolyte solutions in both compartments were replaced completely with $0.2 \mathrm{M}$ phosphate buffer solution $\mathrm{pH}$ 7.0. A constant potential at $-0.75 \mathrm{~V}$ was applied under $\mathrm{CO}_{2}$-saturated condition. In the cathode compartment, the clear buffer solution became partly cloudy because of the remaining medium absorbed in the CF electrode. Thus, the solution was replaced again with the buffer solution.

In all MECs, the experiments were performed in the twocompartment three-electrode set-up contained $0.2 \mathrm{M}$ phosphate buffer solution equipped with the biofilm-coated CF (or biofilm-coated PNR/CF in MEC3) working electrode, a $\mathrm{Ag} / \mathrm{AgCl}$ 

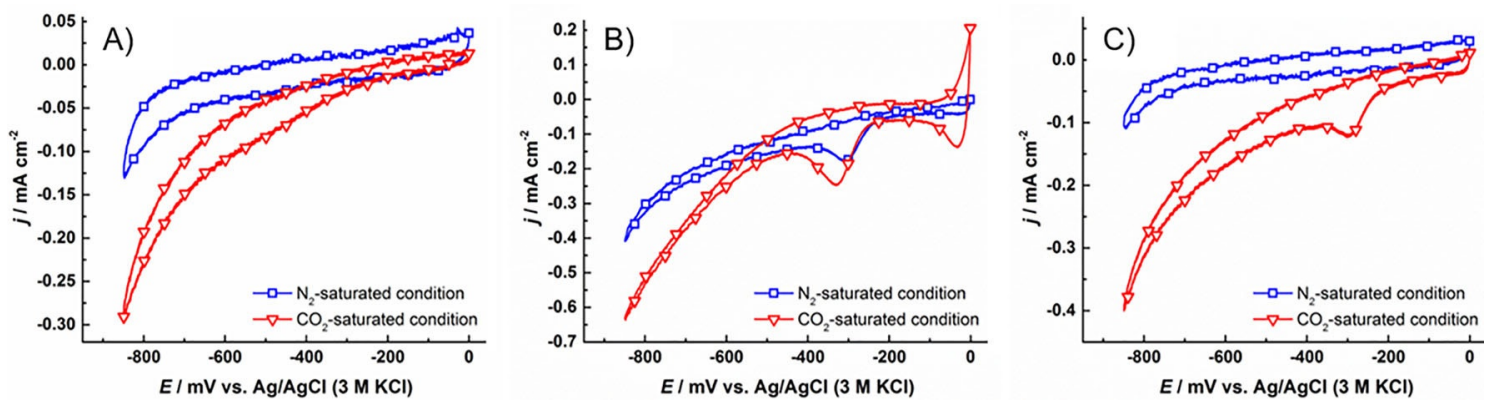

Figure 6. Cyclic voltammograms of biocathodes in A) MEC 1, B) MEC 2 and C) MEC 3 were recorded at potentials between 0 to $-850 \mathrm{mV}$ vs. $\mathrm{Ag} / \mathrm{AgCl}$ ( $3 \mathrm{M} \mathrm{KCl}$ ) with a scan rate of $1 \mathrm{mV} \mathrm{s}^{-1}$ in $0.2 \mathrm{M}$ phosphate buffer solution pH 7.0 (with $50 \mu \mathrm{M}$ of neutral red for MEC 2) saturated with $\mathrm{N}_{2}(\square)$ and $\mathrm{CO}_{2}(\nabla)$.

$(3 \mathrm{M} \mathrm{KCl})$ reference electrode and a Pt plate counter electrode. The resulting biocathodes were characterized electrochemically by cyclic voltammetry under $\mathrm{N}_{2}$ - and $\mathrm{CO}_{2}$-saturated conditions and these results are shown in Figure 6 in blue and red lines, respectively. In all MECs, there is an increase in reductive current starting from $-300 \mathrm{mV}$ observed for $\mathrm{CO}_{2}$-saturated systems as compared to $\mathrm{N}_{2}$-saturated conditions indicating $\mathrm{CO}_{2}$ reduction as the predominant reaction. In the CVs of MEC 1 , the reductive currents are lower compared to MEC 2 and MEC 3, showing enhancement in the electron-transfer processes in the presence of neutral red as a redox mediator. The reductive peaks at around $-300 \mathrm{mV}$ in the CVs that were recorded in MEC 2 and 3 systems belonged to the reductive peaks of neutral red monomer. The observation of neutral red monomer peak in MEC 3 is assumed that it come from the degradation of poly(neutral red).

The long-term performance studies of all MECs for the reduction of $\mathrm{CO}_{2}$ to formate were studied by applying a constant potential at $-0.75 \mathrm{~V}$ under $\mathrm{CO}_{2}$-saturated condition. The electrolysis was monitored by investigating the amount of formate produced in the solution using ion chromatography (IC) and the component of headspace gas using GC. The cathodic chamber was purged with $\mathrm{CO}_{2}$ for $2 \mathrm{~h}$ every 2 days to keep the system saturated with $\mathrm{CO}_{2}$ and the electrolyte solution was replaced every 3-4 weeks. MEC 1 was monitored over 8 weeks. In MEC 2, the experiment was performed in the presence of dissolved neutral red with a concentration of $50 \mu \mathrm{M}$ in the cathodic electrolyte solution and was monitored over 12 weeks. Additionally, MEC 3 was developed and studied for 17 weeks. The running time of each MEC was limited to practical issues. According to the chromatography results, formate was the only product observed in all MECs. During the study, the electrolyte solution was replaced with a new solution every 3-4 weeks. Each electrolyte replacement was labelled sequentially, namely cycles $1-4$. Figure 7 shows the plot of accumulative formate concentration and electrical charges consumed during each cycle and the results are summarized in Table 1. Moreover, the plots were linearly fitted (shown as dashed lines), resulting to the rates of formate production and charge consumption. In case of the overall running period, the estimated production rate was calculated from the total amount of produced formate and charges. In MEC 1, formate production was found to be moderately stable and reached
2.0 and $1.1 \mathrm{~mm}$ in cycles 1 and 2, with formate production rates of 66.7 and $71.7 \mu \mathrm{m} /$ day, respectively. The corresponding \%FEs were found to be 3 and $2 \%$. In MEC 2, the produced formate concentration reached $2.9,2.4$ and $1.0 \mathrm{~mm}$ in cycles 1,2

A)

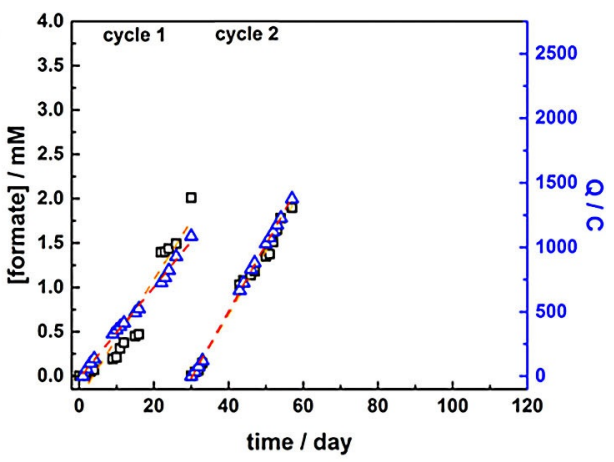

B)

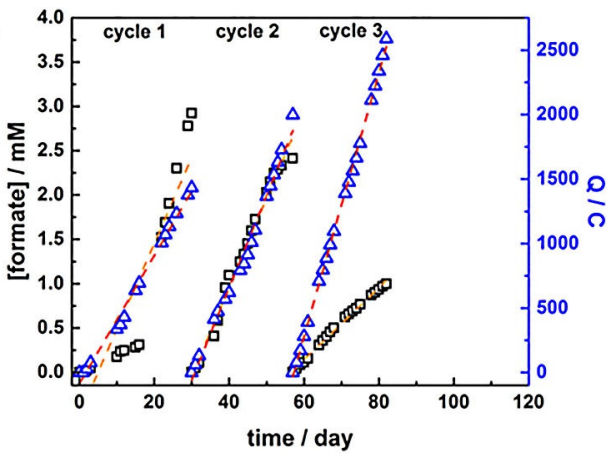

C)

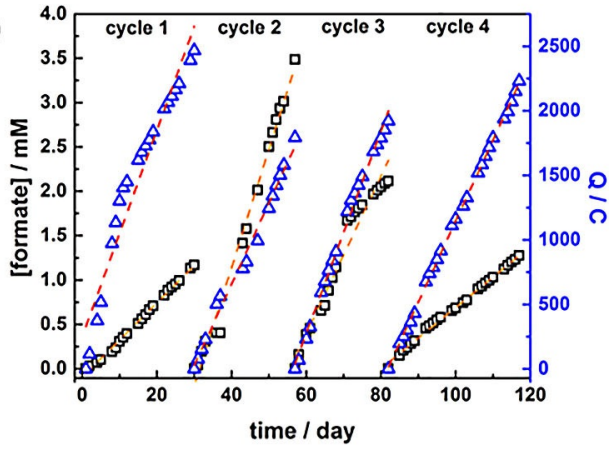

Figure 7. Plots of accumulated formate concentration ( $\square$ ), accumulated electrical charges $(Q ; \triangle)$ of A) MEC 1 for 8 weeks, B) MEC 2 for 12 weeks and C) MEC 3 for 17 weeks. The dashed orange and red lines show linear fitting curve in each cycle of formate concentration and charges, respectively. 


\begin{tabular}{|c|c|c|c|c|c|c|c|}
\hline System & & $\begin{array}{l}\text { Cycle } 1 \\
\text { (30 days) }\end{array}$ & $\begin{array}{l}\text { Cycle } 2 \\
\text { (27 days) }\end{array}$ & $\begin{array}{l}\text { Cycle } 3 \\
\text { (25days) }\end{array}$ & $\begin{array}{l}\text { Cycle } 4 \\
\text { (31 days) }\end{array}$ & 57 days & Overall \\
\hline \multirow[t]{5}{*}{ MEC 1} & [formate] / mM & 2.0 & 1.9 & - & - & 3.9 & 3.9 \\
\hline & $\mathrm{Q} / \mathrm{C}$ & 1086.4 & 1376.3 & - & - & 2462.7 & 2462.7 \\
\hline & production rate / $\mu \mathrm{M}$ day $^{-1}$ & 66.7 & 71.9 & - & - & 68.6 & 68.6 \\
\hline & Q rate / C day ${ }^{-1}$ & 35.3 & 51.9 & - & - & 43.2 & 43.2 \\
\hline & $\% \mathrm{FE}$ & 3 & 2 & - & - & 2 & 2 \\
\hline \multirow[t]{5}{*}{ MEC 2} & [formate] / mM & 2.9 & 2.4 & 1.0 & - & 5.3 & 6.3 \\
\hline & $\mathrm{Q} / \mathrm{C}$ & 1432.3 & 1997.6 & 2588.1 & - & 3429.9 & 6018.0 \\
\hline & production rate $/ \mu \mathrm{M} \mathrm{day}^{-1}$ & 96.9 & 99.8 & 40.7 & - & 93.7 & 77.3 \\
\hline & $\mathrm{Q}$ rate $/ \mathrm{Cday}^{-1}$ & 49.8 & 71.7 & 102.2 & - & 60.2 & 73.4 \\
\hline & $\%$ FE & 8 & 5 & 1 & - & 6 & 4 \\
\hline \multirow[t]{5}{*}{ MEC 3} & [formate] / mM & 1.2 & 3.5 & 2.1 & 1.3 & 4.7 & 8.1 \\
\hline & $\mathrm{Q} / \mathrm{C}$ & 2466.9 & 1793.7 & 1920.6 & 2231.2 & 4260.6 & 8412.5 \\
\hline & production rate / $\mu \mathrm{M}$ day $^{-1}$ & 42.1 & 133.5 & 88.8 & 34.4 & 81.7 & 67.8 \\
\hline & $\mathrm{Q}$ rate $/ \mathrm{Cday}^{-1}$ & 80.1 & 63.0 & 78.3 & 62.9 & 74.7 & 71.9 \\
\hline & $\% \mathrm{FE}$ & 2 & 8 & 4 & 2 & 4 & 4 \\
\hline
\end{tabular}

and 3 , respectively. The production rate increased significantly after the 16th running day in cycle 1 , with the production rate of $96.9 \mu \mathrm{M} \mathrm{day}^{-1}$ for the first cycle. After that, the rate went down to 99.8 and $40.7 \mu \mathrm{M}_{\text {day }}{ }^{-1}$ in cycles 2 and 3, respectively. While the current density of the system increased in every cycle. Consequently, calculated \%FEs were substantially lower from $8 \%$ in the first cycle, to 5 and $1 \%$ in the second and third cycle, respectively. In case of MEC 3, formate was produced slowly in the first cycle with the rate of $42.1 \mu \mathrm{M} \mathrm{day}^{-1}$ and then reached the highest production rate of $133.5 \mu \mathrm{M}$ day $^{-1}$ in the second cycle. The rate decreased gradually to 88.8 and $34.4 \mu \mathrm{m}$ day $^{-1}$ in the third and fourth cycle, respectively. The current density remained stable and \%FEs were found to be 2 , 8,4 and $2 \%$, in cycles 1, 2, 3 and 4, respectively. For comparison, another set of calculations was done for a 57-day period. The results revealed that with the contribution of neutral red, 36 and $20 \%$ more formate was accumulated in MEC 2 and MEC 3, respectively. However, we found out that after the second cycle, the systems containing neutral red were broken down, which might indicate that neutral red and poly(neutral red) degrade during the experiment. Compared to the previous report of the MEC-containing methylobacterium, in which methyl viologen was used as an electron mediator, formate accumulated to reach a concentration of about $10 \mathrm{~mm}$ in $20 \mathrm{~h} .{ }^{[51]}$ However, the cell reaction duration was only up to $80 \mathrm{~h}$ due to the unstable character of methyl viologen. Additionally, methyl viologen (also known as paraquat, a herbicide) is toxic to mammals therefore using methyl viologen is not desirable. Regarding these practical issues, neutral red systems are more promising.

The mechanism of the electron transfer via neutral red mediator is not clear. It can be a redox mediator and/or a biological mediator. One of the proposed mechanisms of neutral red as a redox mediator in the homogeneous approach is presented in Scheme 1. When dissolved in neutral $\mathrm{pH}$ water, neutral red is in its acidic form $\left(\mathrm{NRH}^{+}\right)$. While applying potential at $-0.750 \mathrm{~V}$ versus $\mathrm{Ag} / \mathrm{AgCl}(3 \mathrm{M} \mathrm{KCl}), \mathrm{NRH}^{+}$will be electrochemically reduced $\left(\mathrm{NRH}_{2} ; E^{0}=-0.535 \mathrm{~V}\right.$ vs. $\mathrm{Ag} / \mathrm{AgCl}(3 \mathrm{M} \mathrm{KCl})$ for $\mathrm{NRH}_{2} /$

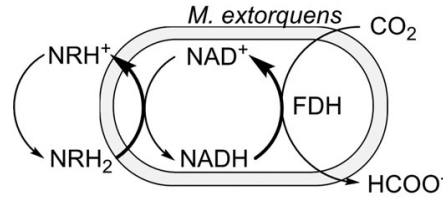

Scheme 1. Proposed reaction mechanism at the electrode in the presence of neutral red. The NADH mechanism is intrinsically involved in living cells.

$\left.\mathrm{NRH}^{+}\right) .{ }^{[54]}$ The resulting $\mathrm{NRH}_{2}$ diffuses into the inner cytoplasmic membrane and then is oxidized into $\mathrm{NRH}^{+}$with the transfer of two electrons and one proton for the reduction of $\mathrm{NAD}^{+}$ to $\mathrm{NADH}\left(E^{0}=-0.530 \mathrm{~V}\right.$ vs. $\mathrm{Ag} / \mathrm{AgCl}(3 \mathrm{M} \mathrm{KCl})$ for $\mathrm{NAD}^{+}$ /NADH). ${ }^{[54]} \mathrm{NADH}$ is known to be an essential coenzyme in the enzymatic reduction of $\mathrm{CO}_{2}$ to formate, catalyzed by formate dehydrogenase, and the reaction takes place inside the microbial cells. Consequently, with the presence of neutral red in the system, the electron transfer from the electrode to the reaction sites is greatly improved, thus higher production rates could be achieved. In addition, using immobilized redox mediators provides a practical system because the mediator is attached onto the electrode, thus, the problems of mediator contamination and product separation could be excluded. Additionally, PNR/CF was found out to be a suitable support for the microorganisms since better coverage of biofilm was observed on the electrode as shown in Figure 2B and C, S1 and S2. It is attributed to higher nitrogen to carbon ratio from amine groups of poly(neutral red) coated onto the electrode which promote the bacteria adhesion to the electrode. ${ }^{[67-69]}$

Another set of control experiments were made in order to confirm that without bacteria, even when using neutral red, no formate production could be observed. The experiments were performed in a similar set-up containing $0.2 \mathrm{M}$ phosphate buffer solution $\mathrm{pH} 7.0$ equipped with a CF electrode without microorganisms inoculated on the electrode. The first experiment was done by applying a constant potential of $-0.75 \mathrm{~V}$ under $\mathrm{N}_{2}$-saturated conditions for a week. After that, the cath- 
ode chamber was purged with $\mathrm{CO}_{2}$ for $2 \mathrm{~h}$ and the cell was monitored for an additional week. Then, neutral red solution was added into the cathodic solution and the experiment continued for another week. In all cases no formate production could be observed, confirming again that the $\mathrm{CO}_{2}$ reduction can only occur when the bio-catalyst is present on the CF electrode (as shown in Figure S7).

To clarify the source of the carbon, another control experiment was done in MEC 2 by applying constant potential at $-0.75 \mathrm{~V}$ under $\mathrm{N}_{2}$-saturated atmosphere. The electrolysis was monitored by investigating the formate concentration and headspace sample analyzed with ion and gas chromatography, respectively. The results show that no formate product or any gas products was observed during the control experiments. This information confirmed that the observed formate was produced by $M$. extorquens inoculated on the CF electrode with $\mathrm{CO}_{2}$ as the carbon source in the system.

\section{Characterization by electrochemical impedance spectroscopy}

The electrochemical impedance experiments were performed in order to characterize the microbial electrochemical set-up. The Bode plot for the two-electrode systems is shown in Figure $8 \mathrm{~A}$ and all data is summarized in Table 2. Measured with the two-electrode system $(\mathrm{Pt}-\mathrm{Pt})$, the resistance of the $0.2 \mathrm{M}$ phosphate buffer solution $\mathrm{pH} 7.0\left(R_{\mathrm{sol}}\right)$ was $85.0 \Omega \mathrm{cm}^{-2}$. Additionally, the resistance of the Nafion membrane $\left(\mathrm{R}_{\mathrm{NF}}\right)$ was determined as $0.87 \mathrm{k} \Omega \mathrm{cm}^{-2}$. In the obtained electrical circuit, the resistance of the electrolyte and the Nafion membrane are connected in series with each other. The resistance of the working electrodes $\left(R_{\mathrm{WE}}\right)$, which are the bare CF electrode and the one coated with the biofilm, were observed as 60.5 and $462.0 \mathrm{k} \Omega \mathrm{cm}^{-2}$, respectively. The constant phase element (CPE) was used for the description of non-ideal capacity of the sponge-like CF electrode. Hence, the resistance of the biofilm was found to be $65.6 \mathrm{k} \Omega \mathrm{cm}^{-2}$ and the capacitance of the CF coated with the biofilm of $M$. extorquens is calculated as $0.058 \mathrm{~F} \mathrm{~cm}^{-2}$. Based on the electrochemical impedance spectroscopy results, the two-compartment configuration was characterized in detail and indicated negligible losses of the system. To characterize the whole electrochemical set-up, an
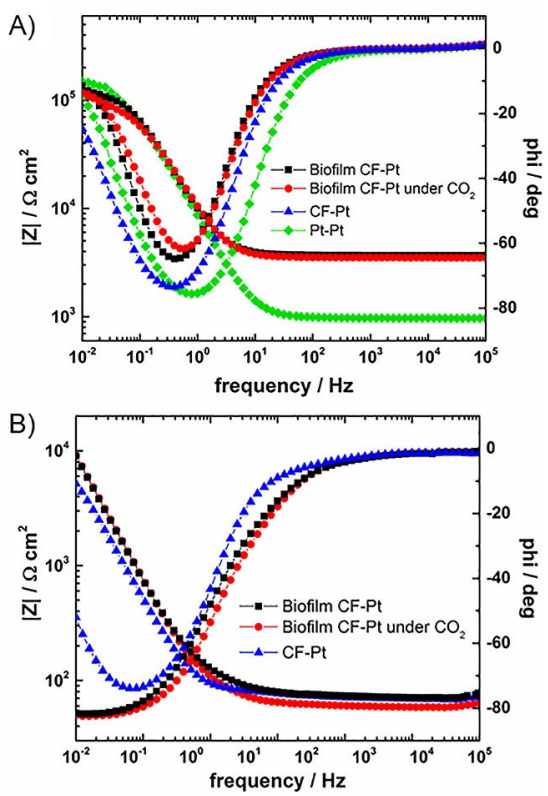

Figure 8. Bode plots of A) four different two-electrode configurations includ ing biofilm coated $\mathrm{CF}$ and Pt under $\mathrm{N}_{2}$-saturated condition $(\mathbf{\square})$, under $\mathrm{CO}_{2}$ saturated condition $(\bullet)$, bare CF and Pt $(\boldsymbol{\Delta})$, and Pt and Pt systems $(\bullet)$, and B) three different three-electrode configurations including biofilm coated CF

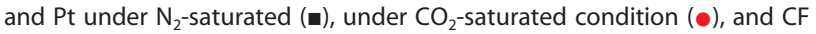
and Pt systems ( $\mathbf{\Delta})$.

$\mathrm{Ag} / \mathrm{AgCl}$ reference electrode was introduced into the cell. The Bode plot of the three-electrode set-up is shown in Figure $8 \mathrm{~B}$ and the corresponding data is summarized in Table 2. For the complete analysis of the electrochemical impedance spectroscopy, the IviumSoft developed by Ivium Technologies was applied as the evaluation program. Based on the fit of the electrochemical impedance spectra, the values listed in Table 2 were extracted. The electrochemical circuits used therefore, are provided in the Figure $S 8$ in combination with the fitting plot. The corresponding Nyquist plots are also provided in the Supporting Information (Figure S9).

\section{Conclusions}

We studied the electrocatalysis of biofilm consisting of $M$. extorquens for the electrochemical reduction of $\mathrm{CO}_{2}$ to formate.

Table 2. List of impedance data for the two-electrode and three-electrode systems.

\begin{tabular}{|c|c|c|c|c|c|c|c|c|}
\hline Condition & WE & $R_{\mathrm{sol}} / \Omega \mathrm{cm}^{-2}$ & $R_{\mathrm{WE}} / \mathrm{k} \Omega \mathrm{cm}^{-2}$ & $R_{\mathrm{NF}} / \mathrm{k} \Omega \mathrm{cm}^{-2}$ & $R_{\mathrm{Bac}} / \mathrm{k} \Omega \mathrm{cm}^{-2}$ & $C_{\mathrm{Bac}} / \mathrm{Fcm}^{-2}$ & CPE-T & CPE-P \\
\hline \multicolumn{9}{|c|}{ Two-electrode system } \\
\hline $0.2 \mathrm{M} \mathrm{PB} \mathrm{pH} 7.0$ & Pt & 85.0 & 159.4 & 0.87 & - & - & 0.0028 & 10.4 \\
\hline $0.2 \mathrm{M} \mathrm{PB} \mathrm{pH} 7.0$ & CF & 317.5 & 462.0 & 3.2 & - & - & 0.023 & 38.2 \\
\hline $0.2 \mathrm{M} \mathrm{PB} \mathrm{pH} 7.0$ & biofilm CF & 386.1 & 60.5 & 3.2 & 65.6 & 0.058 & 0.095 & 34.7 \\
\hline $\begin{array}{l}0.2 \mathrm{M} \mathrm{PB} \mathrm{pH} 7.0 \\
\text { saturated with } \mathrm{CO}_{2} \\
\text { Three-electrode sys }\end{array}$ & biofilm CF & 364.6 & 81.9 & 3.2 & 30.5 & 0.55 & 0.035 & 39.1 \\
\hline 0.2 м PB pH 7.0 & $\mathrm{CF}$ & 71.6 & 9.5 & - & - & - & 3.4 & 37.7 \\
\hline 0.2 м PB pH 7.0 & biofilm CF & 74.5 & 263.5 & - & 38.3 & 2.1 & 2.7 & 40.1 \\
\hline $\begin{array}{l}0.2 \mathrm{M} \mathrm{PB} \mathrm{pH} 7.0 \\
\text { saturated with } \mathrm{CO}_{2}\end{array}$ & biofilm CF & 60.3 & 497.6 & - & 19.4 & 2.4 & 2.7 & 40.0 \\
\hline
\end{tabular}


The formation of the biofilm on the sponge-like carbon-based electrode together with the continuous $\mathrm{H}_{2}$ production was observed during the biofilm growth period. As $M$. extorquens is known as a microorganism capable of reducing $\mathrm{CO}_{2}$ to formate as a part of its metabolism, we studied the utilization of this biofilm for the reduction of $\mathrm{CO}_{2}$ to formate by bio-electrochemical catalysis, purging the system with $\mathrm{CO}_{2}$. The three microbial electrosynthesis cells were set up as described using $\mathrm{CO}_{2}$ as the only carbon source. By applying a constant potential of $-0.75 \mathrm{~V}$ versus $\mathrm{Ag} / \mathrm{AgCl}$, the chromatographic analysis showed that formate was produced from the direct electron injection process from the carbon-based electrode to the microorganisms. Additionally, the effects of neutral red as a redox mediator, were also investigated in the performance of the systems in homogeneous as well as heterogeneous way using an electropolymerized neutral red film on the electrode prior to the growing of the biofilm. The increase in the formate production rate and the Faradaic efficiency of the cells having neutral red is attributed to the improvement of the electron transfer from the electrode onto the biosystems. The heterogeneous approach using poly(neutral red) provides a simplification of the system as it reduces the contamination and product separation in the reaction chamber. Long-term studies of up to 17 weeks demonstrated continuous formate formation, showing the stability and sustainability of the bio-electrosynthesis systems. Further investigations are underway and we strongly propose these microbial electrosynthesis systems for renewable energy storage (chemical energy storage using $\mathrm{CO}_{2}$ conversion), $\mathrm{CO}_{2}$ reduction in general (CCU) and bio(electro)catalysis for other biotechnological conversions.

\section{Experimental Section}

Chemicals, materials and methods: Carbon felt electrodes were purchased from SGL Carbon $\mathrm{GmbH}$ and a Pt wire was used for the electrical contact. Nafion perfluorinated membrane (Nafion 324) was purchased from Sigma-Aldrich. All chemicals were of analytical grade, purchased from commercial sources and used without further purification. The phosphate buffer (PB) solutions were prepared from appropriate amounts of $\mathrm{K}_{2} \mathrm{HPO}_{4}$ and $\mathrm{KH}_{2} \mathrm{PO}_{4}$ solution to reach desired $\mathrm{pH}$ value.

The glass substrates were cleaning via sonication for 15 mins each in acetone, 2\% Hellmanex solution, deionized water and 2-propanol at the last step. Then, the glass substrates were treated in an evaporation chamber for thermal evaporation of $5 \mathrm{~nm}$ chromium followed by $80 \mathrm{~nm}$ gold as being the $\mathrm{Cr} / \mathrm{Au}$ substrate for FTIR measurement. A transparent $\mathrm{Cr} / \mathrm{Au}$-coated glass electrode was prepared in a similar manner with thickness of $3 \mathrm{~nm}$ chromium and $15 \mathrm{~nm}$ gold for UV/Vis measurement., the $\mathrm{Cr} / \mathrm{Au}$ electrode was used with the thickness of $5 \mathrm{~nm}$ of chromium and $80 \mathrm{~nm}$ of gold. For UV/Vis measurement, the transparent $\mathrm{Cr} / \mathrm{Au}$ electrode was used with the thickness of $3 \mathrm{~nm}$ of chromium and $15 \mathrm{~nm}$ of gold. The absorption spectra were recorded on a PerkinElmer Lambda 1050 UV/Vis/NIR spectrophotometer.

ATR-FTIR spectra of neutral red and poly(neutral red) were recorded on a Bruker Vertex 80-ATR machine over 128 scans. The absorption spectra of neutral red aqueous solution and films were measured at room temperature on a PerkinElmer Lambda 1050 UV/Vis/
NIR spectrophotometer. The monomer film was prepared by dropcasting aqueous solution of neutral red at the concentration of $0.5 \mathrm{mg} \mathrm{mL}^{-1}$ on a transparent $\mathrm{Cr} / \mathrm{Au}$ electrode.

SEM images were obtained using JEOL JSM-6360 LV scanning electron microscope at the accelerating voltage of $7.0 \mathrm{kV}$.

Methylobacterium extorquens pure culture: M. extorquens DSM1337 was obtained from the Deutsche Sammlung Mikroorganismen und Zellkulturen (DSMZ). The medium used for cultivation containing polypeptone $\left(10 \mathrm{gL}^{-1}\right)$, yeast extract $\left(2 \mathrm{gL}^{-1}\right)$, and $\mathrm{MgSO}_{4} \cdot 7 \mathrm{H}_{2} \mathrm{O}\left(2 \mathrm{~g} \mathrm{~L}^{-1}\right)$ and supplemented with $0.5 \%(\mathrm{w} / \mathrm{v})$ methanol. $\mathrm{Na}_{2} \mathrm{WO}_{4}$ and $\mathrm{Na}_{2} \mathrm{MoO}_{4}$ were added separately to the medium to a final concentration of $0.3 \mu \mathrm{m}$ each. The $\mathrm{pH}$ was adjusted to a value of 7.0 after autoclaving. $M$. extorquens cultures were routinely grown in an incubator at $30^{\circ} \mathrm{C}$ at $100 \mathrm{rpm}$.

Electrochemical studies: All electrochemical experiments were carried out using an IVIUM CompactStat (The Netherlands) instrument and the potential values reported in this work referred to $\mathrm{Ag} / \mathrm{AgCl}(3 \mathrm{M} \mathrm{KCl})$.

Preparation of poly(neutral red) coated on a carbon felt electrode (PNR/CF)

Set-up: The experiments were performed in a one-compartment electrochemical cell with three-electrode system. A CF $(2.5 \times 5.6 \times$ $0.6 \mathrm{~cm}^{3}$ ) electrode, a $\mathrm{Ag} / \mathrm{AgCl}(3 \mathrm{M} \mathrm{KCl})$ electrode and a Pt plate $\left(1.4 \times 4.1 \mathrm{~cm}^{2}\right)$ were used as a working electrode, a reference electrode and a counter electrode, respectively.

Electrochemical polymerization of neutral red: Following the previous report, ${ }^{[55]}$ before use, the CF electrode was electrochemically pre-treated in $0.1 \mathrm{M} \mathrm{KNO}_{3}$ aqueous solution at potentials between 0 and $1.0 \mathrm{~V}$ with the scan rate of $50 \mathrm{mV} \mathrm{s}^{-1}$ over 20 cycles. After that, the electropolymerization of neutral red was carried out at potentials between -1.0 and $1.0 \mathrm{~V}$ with the scan rate of $50 \mathrm{mV} \mathrm{s}^{-1}$ over 20 cycles in $0.1 \mathrm{M}$ phosphate buffer solution $\mathrm{pH} 6.0$ containing $1 \mathrm{~mm}$ neutral red and $0.1 \mathrm{M} \mathrm{KNO}_{3}$, yielding a poly(neutral red) coated CF (PNR/CF). The PNR/CF electrode was electrochemically characterized at potentials between -1.0 and $1.0 \mathrm{~V}$ at different scan rates of 5, 10, 25, 50 and $100 \mathrm{mV} \mathrm{s}^{-1}$. For FTIR and UV/Vis measurements, the poly(neutral red) was electropolymerized onto $\mathrm{Cr} / \mathrm{Au}$-coated glass electrodes with the similar manner to the CF electrode.

\section{Microbial electrosynthesis studies}

Set-up and electrolytes: The inoculation and microbial electrosynthesis experiments were carried out in the two-compartment electrochemical cell of which the anode and cathode compartments were separated by a pretreated Nafion membrane, allowing proton transport in the system. The membrane was prepared by soaking a commercial Nafion 324 sheet in a $3 \mathrm{M} \mathrm{HCl}$ solution for $2 \mathrm{~h}$ followed by boiling the membrane in deionized water for an additional $30 \mathrm{~min}$. The three-electrode cell consists of CF or PNR/CF $(2.5 \times$ $\left.6.5 \times 0.6 \mathrm{~cm}^{3}\right)$ electrode as a working electrode, a $\mathrm{Ag} / \mathrm{AgCl}(3 \mathrm{M} \mathrm{KCl})$ reference electrode and a Pt plate $\left(1.4 \times 4.1 \mathrm{~cm}^{2}\right)$ counter electrode. The anode compartment contained $0.2 \mathrm{M}$ phosphate buffer solution pH 7.0 as a supporting electrolyte solution. For the biofilm growth phase, the cathodic electrolyte was a medium consisting of the following nutrients: polypeptone $\left(10 \mathrm{~g} \mathrm{~L}^{-1}\right)$, yeast extract $\left(2 \mathrm{~g} \mathrm{~L}^{-1}\right), \mathrm{MgSO}_{4} \cdot 7 \mathrm{H}_{2} \mathrm{O}\left(2 \mathrm{~g} \mathrm{~L}^{-1}\right)$, methanol $(0.5 \% \mathrm{w} / \mathrm{v})$ and $\mathrm{Na}_{2} \mathrm{WO}_{4}$ $(0.3 \mu \mathrm{M}) .{ }^{\left[{ }^{11]}\right.}$ During the microbial electrosynthesis studies, $0.2 \mathrm{M}$ phosphate buffer solution pH 7.0 was used as cathodic electrolyte solution. 
Inoculation of microorganisms: The formation of biofilm on CF electrodes was done in the aforementioned electrochemical set-up in which the cathodic electrolyte solution contained $10 \%(\mathrm{v} / \mathrm{v})$ of $M$. extorquens pure culture and afterwards purged with $\mathrm{CO}_{2}$ for $2 \mathrm{~h}$. A constant potential at $-0.75 \mathrm{~V}$ was applied for a month with weekly $\mathrm{CO}_{2}$ purging. During this period, $2 \mathrm{~mL}$ of headspace samples were collected daily and injected into a gas chromatography (GC) for the analysis of headspace products $\left(\mathrm{CH}_{4}, \mathrm{CO}\right.$ and $\left.\mathrm{H}_{2}\right)$. After one-month inoculation of the M. extorquens, the biofilm formation on the electrode could be observed. The medium was removed and replaced one or two times with $0.2 \mathrm{M}$ phosphate buffer solution $\mathrm{pH} 7.0$ in order to get rid of the remaining media that went inside the sponge-like CF electrodes.

Long-term microbial electrosynthesis studies: In this work, 3 different microbial electrosynthesis cells (MEC 1, 2 and 3) were investigated. For all MECs, the long-term electrolysis was conducted constantly at applied potential of $-0.75 \mathrm{~V}$ under $\mathrm{CO}_{2}$-saturated condition. The cathodic chambers were purged weekly with $\mathrm{CO}_{2}$ for $2 \mathrm{~h}$ in order to keep the systems saturated with $\mathrm{CO}_{2}$, and the electrolyte was replaced with new buffer solutions every 3-4 weeks reported as different running cycles. The experiments were continuously performed for 8, 12 and 17 weeks for MEC 1, MEC 2 and MEC 3, respectively. In case of MEC 2, neutral red solution was added into the cathodic electrolyte solution to achieve a final concentration of $50 \mu \mathrm{M}$.

Product analysis: The headspace samples were taken using a gastight syringe and the product analysis for $\mathrm{H}_{2}$ and $\mathrm{CO}$ was done by using a Thermo Scientific Trace GC Ultra equipped with a thermal conductivity detector (TCD). For the formate production analysis, the liquid samples were diluted with deionized water and their concentrations were determined by a Thermo Scientific Dionex5000 ion chromatography (IC) system equipped with an lonPac AG19 guard column $(2 \times 50 \mathrm{~mm})$, a Dionex AS19 column $(2 \times$ $250 \mathrm{~mm}$ ) and a Dionex suppressor-conductivity detector by using gradient concentration of $\mathrm{KOH}$ as eluent. The Faradaic efficiency $(\% \mathrm{FE})$ toward the product is calculated as:

$\% F E=\frac{\text { moles of product }}{\frac{1}{n} \times \text { moles of electron }} \times 100$

in which moles of product are calculated from the amount of $\mathrm{H}_{2}$ or formate produced in the systems, $n$ is the number of electrons needed for reduction (in both $\mathrm{H}_{2}$ and formate production cases, $n=2$ ) and moles of electron are calculated by the dividing of number of charges during electrolysis by Faradaic constant as $96485.33 \mathrm{C} \cdot \mathrm{mol}^{-1}$.

\section{Electrochemical characterization}

Characterization by cyclic voltammetry (CV): The biofilm electrodes were characterized electrochemically after inoculation period, by means of cyclic voltammetry under the $\mathrm{N}_{2}$ - and $\mathrm{CO}_{2}$-saturated conditions for all MECs. CVs were recorded in $0.2 \mathrm{M}$ phosphate buffer solution at pH 7.0 (with $50 \mu \mathrm{M}$ neutral red for MEC2) at potentials between 0 and $-850 \mathrm{mV}$ vs. $\mathrm{Ag} / \mathrm{AgCl}(3 \mathrm{M} \mathrm{KCl})$ with the scan rate of $1 \mathrm{mV} \mathrm{s}^{-1}$ by using a Jaissle Potentiostat-Galvanostat IMP 88 PC.

Characterization by electrochemical impedance spectroscopy (EIS): All impedance experiments were carried out in a two-compartment electrochemical cell separated with a pretreated Nafion membrane. The impedance spectra were recorded in $0.2 \mathrm{M}$ potassium buffer solution $\mathrm{pH} 7.0$ within the frequency range of $10^{5}$ to $10^{-2} \mathrm{~Hz}$ at the perturbation amplitude of $50 \mathrm{mV}$. In order to determine the parameters of the cell, two Pt plates were used as electrodes in the abovementioned set-up as a control experiment. Next, one Pt electrode was replaced by a CF and used as a working electrode. Later on, the CF was replaced by the CF coated with the biofilm. Additionally, a $\mathrm{Ag} / \mathrm{AgCl}(3 \mathrm{M} \mathrm{KCl})$ was introduced to the set-up to achieve the three-electrode, in order to characterize the complete electrochemical cell by the impedance spectroscopy. The vindication for this procedure is explained in more detail in a separate publication. ${ }^{[61]}$

\section{Acknowledgements}

Financial support by the Austrian Climate and Energy Fund within the project CO2TRANSFER (848862) and MELOS (861392) projects is gratefully acknowledged. Further support of the Austrian Science Foundation (FWF) within the Wittgenstein Prize for Prof. Sariciftci is gratefully acknowledged (Z222-N19).

\section{Conflict of Interest}

The authors declare no conflict of interest.

Keywords: bioelectrocatalysis $\cdot \mathrm{CO}_{2}$ reduction - direct electron injection · microbial electrosynthesis $\cdot$ redox mediator

[1] A. P. M. Baede, P. van der Linden, A. Verbruggen, Annex II, to IPCC Fourth Assessment Report 2007.

[2] D. Lüthi, M. Le Floch, B. Bereiter, T. Blunier, J.-M. Barnola, U. Siegenthaler, D. Raynaud, J. Jouzel, H. Fischer, K. Kawamura, T. F. Stocker, Nature 2008, 453, 379-382.

[3] S. Arrhenius, Phil. Mag. S. 5 1896, 41, 237-276.

[4] M. Aresta, A. Dibenedetto, in $\mathrm{CO}_{2}$ Conversion and Utilization, American Chemical Society, 2002, pp. 54-70.

[5] M. Aresta, A. Dibenedetto, Dalton Trans. 2007, 0, 2975.

[6] E. V. Kondratenko, G. Mul, J. Baltrusaitis, G. O. Larrazábal, J. Pérez-Ramírez, Energy Environ. Sci. 2013, 6, 3112.

[7] K. Schuchmann, V. Müller, Science 2013, 342, 1382-1385.

[8] K. B. Cantrell, T. Ducey, K. S. Ro, P. G. Hunt, Bioresour. Technol. 2008, 99, $7941-7953$.

[9] S.-Y. Chiu, C.-Y. Kao, C.-H. Chen, T.-C. Kuan, S.-C. Ong, C.-S. Lin, Bioresour. Technol. 2008, 99, 3389-3396.

[10] D. T. Whipple, P. J. A. Kenis, J. Phys. Chem. Lett. 2010, 1, 3451-3458.

[11] A. A. Peterson, J. K. Nørskov, J. Phys. Chem. Lett. 2012, 3, 251-258.

[12] Y. Hori, K. Kikuchi, S. Suzuki, Chem. Lett. 1985, 14, 1695-1698.

[13] K. P. Kuhl, E. R. Cave, D. N. Abram, T. F. Jaramillo, Energy Environ. Sci. 2012, 5, 7050 .

[14] T. Inoue, A. Fujishima, S. Konishi, K. Honda, Nature 1979, 277, 637-638.

[15] C. Wang, Z. Xie, K. E. deKrafft, W. Lin, J. Am. Chem. Soc. 2011, 133, $13445-13454$.

[16] B. Kumar, M. Llorente, J. Froehlich, T. Dang, A. Sathrum, C. P. Kubiak, Annu. Rev. Phys. Chem. 2012, 63, 541-569.

[17] J. Hawecker, J.-M. Lehn, R. Ziessel, Helv. Chim. Acta 1986, 69, 1990 2012.

[18] J. M. Lehn, R. Ziessel, Proc. Natl. Acad. Sci. USA 1982, 79, $701-704$.

[19] H. A. Hansen, J. B. Varley, A. A. Peterson, J. K. Nørskov, J. Phys. Chem. Lett. 2013, 4, 388-392.

[20] J. Shen, R. Kortlever, R. Kas, Y. Y. Birdja, O. Diaz-Morales, Y. Kwon, I. Ledezma-Yanez, K. J. P. Schouten, G. Mul, M. T. M. Koper, Nat. Commun. 2015, 6, 8177.

[21] C. Costentin, S. Drouet, M. Robert, J.-M. Savéant, Science 2012, 338, 90 94. 
[22] M. Asadi, B. Kumar, A. Behranginia, B. A. Rosen, A. Baskin, N. Repnin, D. Pisasale, P. Phillips, W. Zhu, R. Haasch, R. F. Klie, P. Král, J. Abiade, A. Salehi-Khojin, Nat. Commun. 2014, 5, 4470.

[23] S. Lin, C. S. Diercks, Y.-B. Zhang, N. Kornienko, E. M. Nichols, Y. Zhao, A. R. Paris, D. Kim, P. Yang, O. M. Yaghi, C. J. Chang, Science 2015, 349, $1208-1213$.

[24] R. Kortlever, I. Peters, S. Koper, M. T. M. Koper, ACS Catal. 2015, 5, 3916 3923.

[25] Y. Chen, C. W. Li, M. W. Kanan, J. Am. Chem. Soc. 2012, 134, $19969-$ 19972.

[26] C. W. Li, M. W. Kanan, J. Am. Chem. Soc. 2012, 134, 7231-7234.

[27] Y. Hori, H. Wakebe, T. Tsukamoto, O. Koga, Electrochim. Acta 1994, 39, $1833-1839$.

[28] A. M. Appel, J. E. Bercaw, A. B. Bocarsly, H. Dobbek, D. L. DuBois, M. Dupuis, J. G. Ferry, E. Fujita, R. Hille, P. J. A. Kenis, C. A. Kerfeld, R. H. Morris, C. H. Peden, A. R. Portis, S. W. Ragsdale, T. B. Rauchfuss, J. N. Reek, L. C. Seefeldt, R. K. Thauer, G. L. Waldrop, Chem. Rev. 2013, 113 $6621-6658$.

[29] M. Aresta, A. Dibenedetto, C. Pastore, Environ. Chem. Lett. 2005, 3, $113-$ 117.

[30] S. Schlager, A. Fuchsbauer, M. Haberbauer, H. Neugebauer, N. S. Sariciftci, J. Mater. Chem. A 2017, 5, 2429-2443.

[31] N. Long, J. Lee, K.-K. Koo, P. Luis, M. Lee, Energies 2017, 10, 473.

[32] S. Schlager, A. Dibenedetto, M. Aresta, D. H. Apaydin, L. M. Dumitru, H. Neugebauer, N. S. Sariciftci, Energy Technol. 2017, 5, 812-821.

[33] J. Shi, Y. Jiang, Z. Jiang, X. Wang, X. Wang, S. Zhang, P. Han, C. Yang, Chem. Soc. Rev. 2015, 44, 5981-6000.

[34] J. R. Andreesen, L. G. Ljungdahl, J. Bacteriol. 1973, 116, 867-873.

[35] K. Seelbach, B. Riebel, W. Hummel, M.-R. Kula, V.I. Tishkov, A. M. Egorov, C. Wandrey, U. Kragl, Tetrahedron Lett. 1996, 37, 1377-1380.

[36] S. Schlager, H. Neugebauer, M. Haberbauer, G. Hinterberger, N. S. Sariciftci, ChemCatChem 2015, 7, 967-971.

[37] S. Schlager, L. M. Dumitru, M. Haberbauer, A. Fuchsbauer, H. Neugebauer, D. Hiemetsberger, A. Wagner, E. Portenkirchner, N. S. Sariciftci, ChemSusChem 2016, 9, 631-635.

[38] T. Reda, C. M. Plugge, N. J. Abram, J. Hirst, Proc. Natl. Acad. Sci. USA 2008, 105, 10654-10658.

[39] B. A. Parkinson, P. F. Weaver, Nature 1984, 309, 148-149.

[40] B. E. Logan, K. Rabaey, Science 2012, 337, 686-690.

[41] A. Alissandratos, H.-K. Kim, H. Matthews, J. E. Hennessy, A. Philbrook, C. J. Easton, Appl. Environ. Microbiol. 2013, 79, $741-744$.

[42] S. Cheng, D. Xing, D. F. Call, B. E. Logan, Environ. Sci. Technol. 2009, 43, 3953-3958

[43] M. C. A. A. Van Eerten-Jansen, A. Ter Heijne, C. J. N. Buisman, H. V. M. Hamelers, Int. J. Energy Res. 2012, 36, 809-819.

[44] M. Villano, F. Aulenta, C. Ciucci, T. Ferri, A. Giuliano, M. Majone, Bioresour. Technol. 2010, 101, 3085-3090.

[45] L. G. Ljungdhal, Annu. Rev. Microbiol. 1986, 40, 415-450.
[46] K. T. Wieringa, Antonie Van Leeuwenhoek 1936, 3, 263 - 273.

[47] K. T. Wieringa, Antonie Van Leeuwenhoek 1939, 6, 251-262.

[48] S. W. Ragsdale, E. Pierce, Biochim. Biophys. Acta-Proteins Proteomics 2008, 1784, 1873-1898.

[49] J. Schrader, M. Schilling, D. Holtmann, D. Sell, M. V. Filho, A. Marx, J. A. Vorholt, Trends Biotechnol. 2009, 27, 107-115.

[50] S. Belkhelfa, K. Labadie, C. Cruaud, J.-M. Aury, D. Roche, M. Bouzon, M. Salanoubat, V. Döring, Genome Announc. 2018, 6, e00018-18.

[51] H. Hwang, Y. J. Yeon, S. Lee, H. Choe, M. G. Jang, D. H. Cho, S. Park, Y. H. Kim, Bioresour. Technol. 2015, 185, 35-39.

[52] T. D. Harrington, V. N. Tran, A. Mohamed, R. Renslow, S. Biria, L. Orfe, D. R. Call, H. Beyenal, Bioresour. Technol. 2015, 192, 689-695.

[53] D. H. Park, M. Laivenieks, M. V. Guettler, M. K. Jain, J. G. Zeikus, Appl. Environ. Microbiol. 1999, 65, 2912-2917.

[54] D. H. Park, J. G. Zeikus, Appl. Environ. Microbiol. 2000, 66, 1292-1297.

[55] R. Pauliukaite, M. E. Ghica, M. Barsan, C. M. A. Brett, J. Solid State Electrochem. 2007, 11, 899-908.

[56] D. R. Shobha Jeykumari, S. Sriman Narayanan, Biosens. Bioelectron. 2008, 23, 1404-1411.

[57] A. A. Karyakin, O. A. Bobrova, E. E. Karyakina, J. Electroanal. Chem. 1995, 399, 179- 184.

[58] Y. Ren, D. Pan, X. Li, F. Fu, Y. Zhao, X. Wang, J. Chem. Technol. Biotechnol. 2013, 88, 1946-1950.

[59] C. Li, L. Ding, H. Cui, L. Zhang, K. Xu, H. Ren, Bioresour. Technol. 2012 $116,459-465$

[60] Y. Zou, C. Xiang, L. Yang, L.-X. Sun, F. Xu, Z. Cao, Int. J. Hydrogen Energy 2008, 33, 4856-4862.

[61] H. Coskun, A. Aljabour, P. De Luna, D. Farka, T. Greunz, D. Stifter, M. Kus, X. Zheng, M. Liu, A. W. Hassel, W. Schöfberger, E. H. Sargent, N. S. Sariciftci, S. Philipp, Sci. Adv. 2017, 3, e1700686.

[62] V. Anesti, J. Vohra, S. Goonetilleka, I. R. McDonald, B. Straubler, E. Stackebrandt, D. P. Kelly, A. P. Wood, Environ. Microbiol. 2004, 6, 820-830.

[63] M. E. Lidstrom, L. Chistoserdova, J. Bacteriol. 2002, 184, 1818.

[64] V. Müller, Appl. Environ. Microbiol. 2003, 69, 6345-6353.

[65] D. Das, T. N. Veziroğlu, Int. J. Hydrogen Energy 2001, 26, 13-28.

[66] C. Yang, J. Yi, X. Tang, G. Zhou, Y. Zeng, React. Funct. Polym. 2006, 66, $1336-1341$

[67] A. Terada, A. Yuasa, T. Kushimoto, S. Tsuneda, A. Katakai, M. Tamada, Microbiology 2006, 152, 3575-3583.

[68] T. Saito, M. Mehanna, X. Wang, R. D. Cusick, Y. Feng, M. A. Hickner, Bioresour. Technol. 2011, 102, 395-398.

[69] S. Cheng, B. E. Logan, Electrochem. commun. 2007, 9, 492-496.

Manuscript received: December 11, 2018

Accepted manuscript online: January 4, 2019

Version of record online: March 12, 2019 